\title{
IMPLEMENTASI MULTI USER OPERATING SYSTEM (OS) DENGAN CCBOOT
}

\author{
Dio Prima Mulya ${ }^{1)}$, Sularno ${ }^{2),}$ Muhammad Razi ${ }^{3)}$ \\ ${ }^{1}$ Sistem Informasi, Universitas Dharma Andalas, J1. Sawahan No.103, Padang (penulis 1) \\ email: dio@unidha.ac.id \\ ${ }^{1}$ Sistem Informasi, Universitas Dharma Andalas, Jl. Sawahan No.103, Padang (penulis 1) \\ email: soelarno@unidha.ac.id \\ ${ }^{1}$ Sistem Informasi, Universitas Dharma Andalas, Jl. Sawahan No.103, Padang (penulis 1) \\ email: razi@unidha.ac.id

\section{Abstract}

The development of hardware and software technology has caused cybercafe and computer labs to raise the level of the operating system installed on their hardware. The Windows 7 operating system that is usually paired with PC devices is not compatible because there is no software update available for the Windows 7 version. At present, the operating system used is WINDOWS 10, but businesses have difficulty implementing or installing WINDOWS 10 on the device. they. One application that is used to facilitate the use of WINDOWS 10 is CCBoot. This research was conducted by directly applying the use of WINDOWS 10 on a Personal Computer (PC) device with an additional CCboot application. From the results of this study will be concluded whether the implementation of a diskless system with CCBoot can optimize the use of hardware.

Keyword: Computer, Operating System, Hardware, Software

Perkembangan teknologi perangkat keras dan perangkat lunak menyebabkan pelaku usaha warnet dan laboratorium komputer menaikan level sistem operasi yang dipasangkan pada hardware yang mereka miliki. Sistem operasi Windows 7 yang biasanya dipasangkan pada perangkat PC sudah tidak kompetibel karena tidak tersedia pembaharuan software untuk versi Windows 7. Pada saat ini, sistem operasi yang di pakai adalah WINDOWS 10, namun pelaku usaha mengalami kesulitan dalam proses implementasi atau instalasi WINDOWS 10 pada perangkat mereka. Salah satu aplikasi yang digunakan untuk mempermudah penggunaan WINDOWS 10 adalah CCBoot. Penelitian ini dilakukan dengan mengaplikasikan langsung penggunaan WINDOWS 10 pada perangkat Personal Computer (PC) dengan aplikasi tambahan CCboot. Dari hasil penelitian ini akan didapatkan kesimpulan apakah dengan diterapkannya sistem diskless dengan CCBoot ini dapat mengoptimalkan penggunaan perangkat keras.

Keywords: Komputer, Sistem Operasi, Hardware, Software

\section{PENDAHULUAN}

Windows OS merupakan sistem operasi yang umum dipasangkan kepada perangkat komputer untuk menjalankan perangkat keras dan perangkat lunak. Windows 7 merupakan sistem operasi yang sering dipakai oleh para pelaku usaha ini, namun dengan berkembangnya perangkat lunak dan perangkat keras tersebut membuat Windows 7 ini tidak dapat digunakan kembali. Para pelaku usaha harus menaikkan ke versi Windows 10 untuk dapat memaksimalkan kinerja dari perangkat-perangkat komputer yang mereka miliki. Para pelaku usaha mengalami kesulitan dalam proses implementasi atau instalasi Windows 10 pada perangkat mereka, dikarenakan karna setup dari setiap hardware yang berbeda beda memaksa server harus memliki image yang banyak. Hal ini membebankan server dalam operasi multi user. Semakin banyak user (komputer) yang hidup semakin besar beban server untuk me-load sistem operasi yang disediakan didalam server. Salah satu aplikasi yang digunakan untuk mempermudah penggunaan Windows 10 
adalah CCBoot. Oleh karena itu, penelitian ini dilakukan untuk mengetahui apakah dengan diterapkannya sistem diskless dengan CCBoot sebagai booting sistem multi user ini dapat mengoptimalkan penggunaan perangkat keras. Hasil Penelitian dengan judul 2 "IMPLEMENTASI MULTI USER OS DENGAN CCBOOT" akan di sajikan sebagai laporan penelitian.

\section{METODE PENELITIAN}

Metodologi yang digunakan dalam melaksanakan kegiatan penelitian ini adalah dengan langkah-langkah sebagai berikut:

1. Penelitian Lapangan Penelitian ini dilakukan demi mendapatkan data langsung dari VEGANET dengan melakukan Observasi dan wawancara langsung kepada teknisi dan pemilik usaha.

2. Studi Literatur. Mencari referensi yang berhubungan dengan diskless.

3. Metoda Konsultasi Melakukan konsultasi dengan stakeholders terkait mengenai diskless dengan menggunakan sistem operasi Windows 10.

4. Perancangan jaringan lokal (LAN) diskless dengan sistem operasi Windows 10.

5. Pembuatan laporan, Dokumentasi dan evaluasi jika perlu ada yang disempurnakan.

6. Adapun spesifikasi hardware dan software yang di gunakan sebagai berikut:

A. Hardware (perangkat keras) Spesifikasi Hardware yang dibutuhkan adalah :

1. Processor intel core i3

2. Memory 16 GB DDR4 dan 320 GB HDD

3. Monitor

4. Laptop

B. Software (perangkat lunak)

1. Sistem Operasi Windows 10

2. Microsoft Office 2016

3. Serta Software pendukung lainnya.

\section{CCBoot}

\section{HASIL DAN PEMBAHASAN}

Adapun kemudahan lain bagi pemilik warnet ataupun laboratorium komputer adalah dalam mengelola perangkat lunak (Software) yang ditanamkan pada setiap komputer klien. Setiap perangkat lunak yang mengharuskan untuk melakukan pembaharuan (update), tidak harus melakukan update pada setiap komputer klien, karena cukup dilakukan pada sisi server diskless, ketika perangkat lunak pada sisi diskless diperbaharui, maka otomatis pada sisi klien juga telah diperbaharui. Ini menghemat dalam penggunaan bandwith internet dan waktu untuk melakukan perbaharuan.

Sehingga dalam pengelolaan software yang disediakan akan lebih mudah dan efisien. Pada sisi penggunaan OS (Operating System) dimana seharusnya setiap klien harus memiliki masing-masing OS, dengan digunakannya diskless maka OS yang harus disediakan hanya 1 (satu) dan digunakan secara bersamaan untuk semua klien.

Sistem kerja diskless ini adalah dengan membuat image yang berisi OS (Operating System) dan software yang akan digunakan secara bersamaan pada komputer klien. Jadi setiap klien akan memanggil image ini melalui jaringan lan, dari sisi server, untuk menjalankannya pada sisi klien.

Setiap pemanggilan image oleh klien dari server, tidak akan berpengaruh pada klien yang lain. Jadi setiap klien dapat melakukan task yang berbeda-beda. Karena hardware yang digunakan oleh klien adalah masing-masing, yang digunakan secara Bersama hanyalah OS (Operating System) dan perangkat Lunak/aplikasi (software).

\section{Proses Instalasi Diskless}


1. Buka CCBoot Setup, Pilij "CCBoot Server Instalation", dan Klik "next"

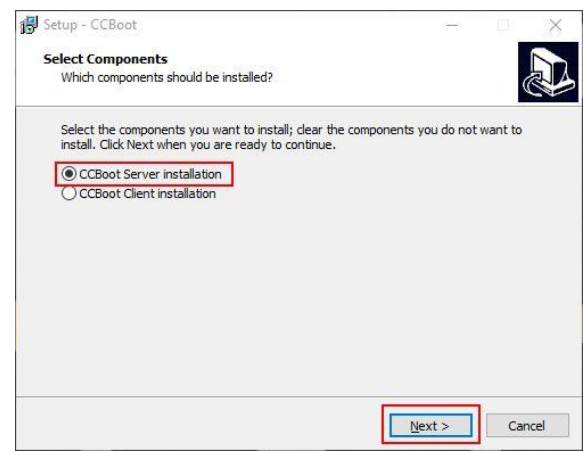

2. Pilih Lokasi tempat penyimpanan (destination Location) dan, klik "next".

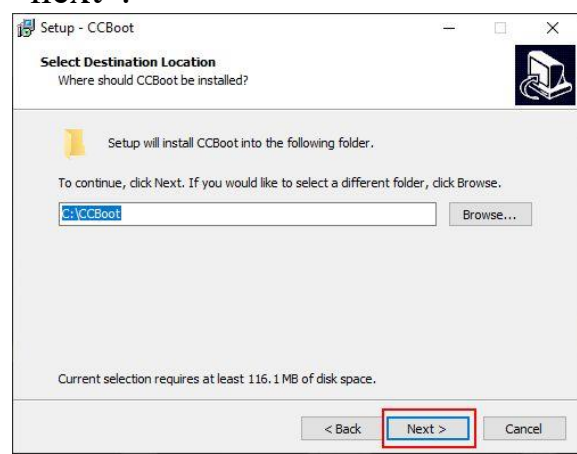

3. Pilih "next" untuk melanjutkan

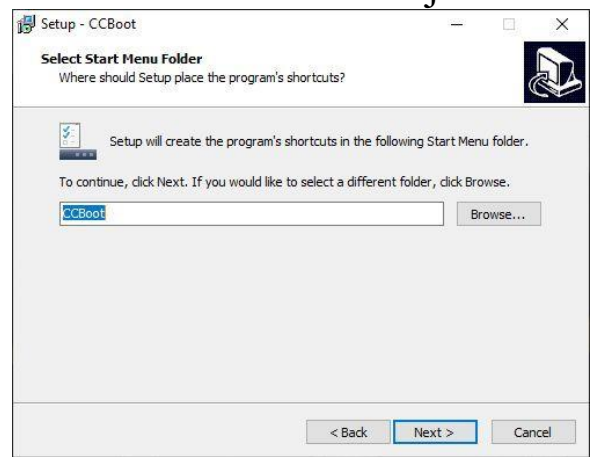

4. Ceklis semua dan pilih "next"

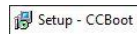

Select Additional Tasks
Which additional tasks sho

Which additional tasks should be performed?

Select the additional tasks you would like Setup to perform while installing CCBO

then dick Next.

Additional shortcuts:

$\square$ Create a desktop shortcut

$\square$ Create a Quick Launch shortar

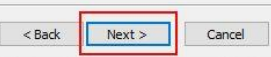

5. Klik tombol "Install" untuk memulai instalasi

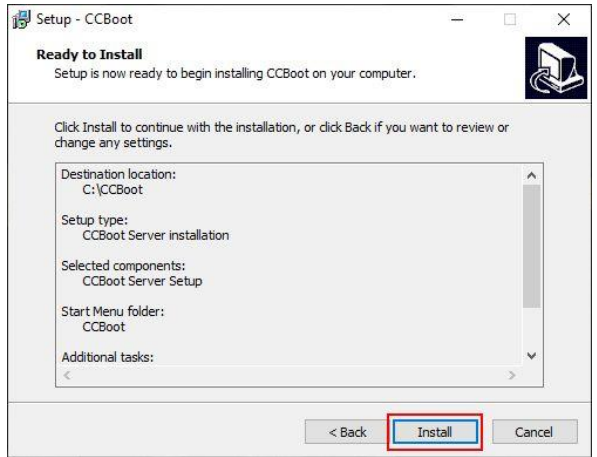

6. Setelah intalasi selesai, ceklis "launch CCBoot" lalu klik "Finish"

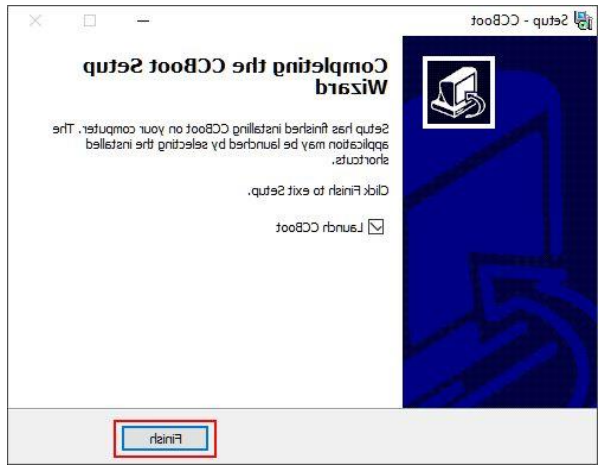

7. Pada popup box pilih "yes" untuk melakukan restart

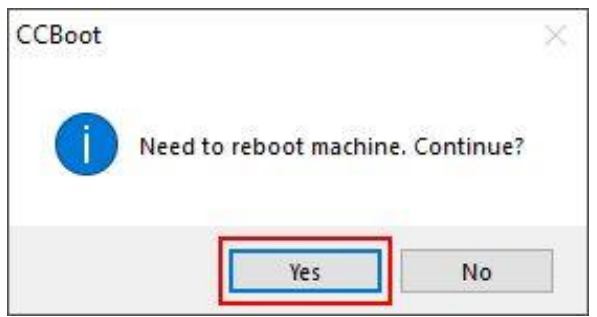

8. Setelah selesai restart, klik CCBoot pada desktop, maka akan tertampil seperti berikut

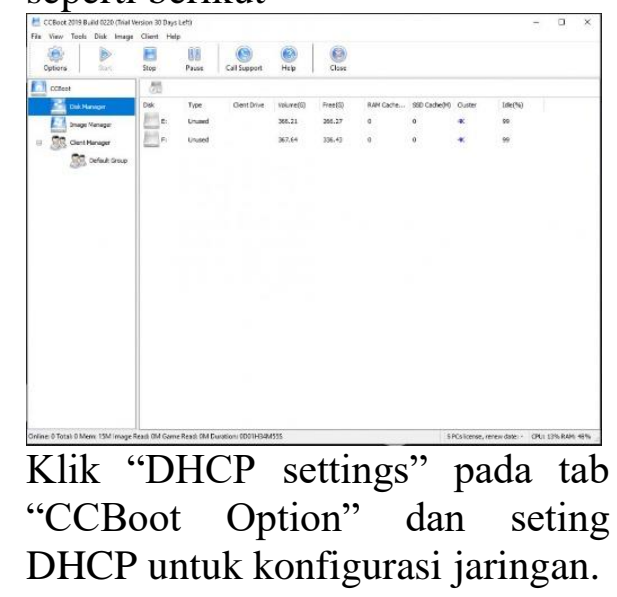




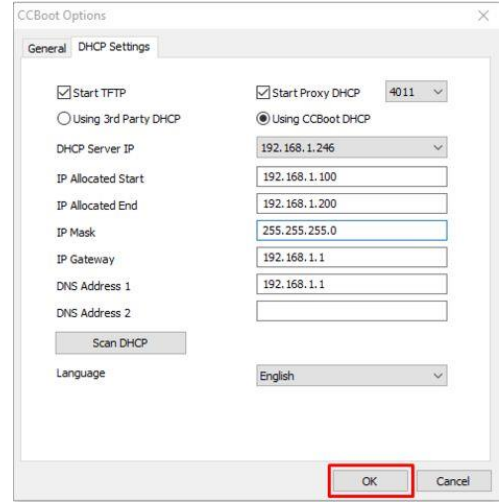

10. Selanjutnya masuk ke "Disk Manager", klik kanan dan pilih "Edit Disk"

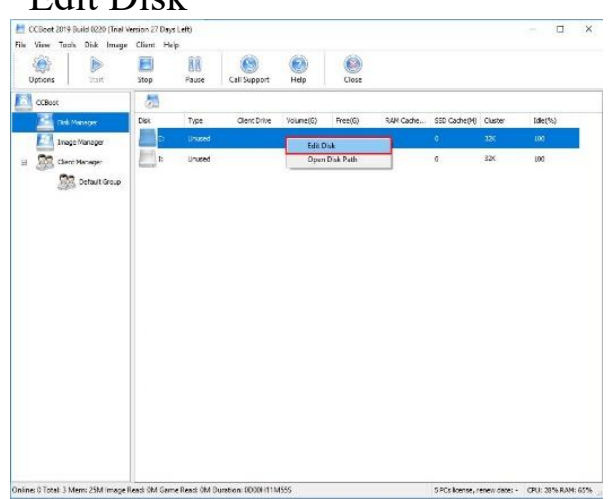

11. Pilih tipe, set RAM Chche, SSD Chache dan pilih "OK"

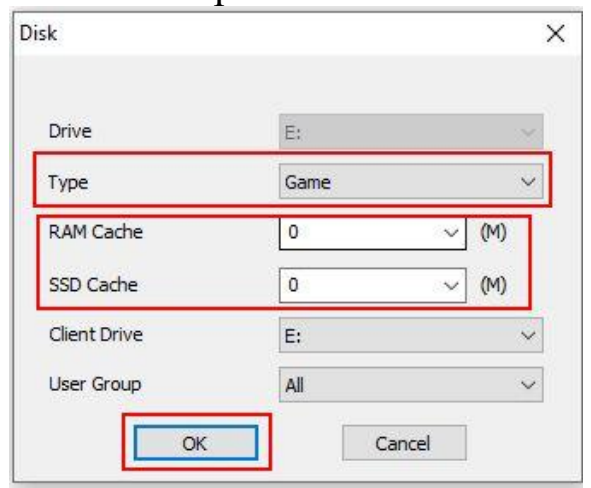

Setelah semua langkah selesai, restart kembali komputer server. Setelah komputer server nyala kembali. Buka lagi CCBoot pada desktop, lalu hidupkan komputer klien.

Pada komputer Klien, masuk ke BIOS lalu pilih "boot from LAN". Lalu lakukan restart pada komputer klien. Setelah restart, maka komputer klien akan meminta alamat ip server, dan nomer klien.
Masukkan sesuai dengan nomer komputer dan IP server yang telah diset sebelumnya.

Lakukan restart kembali, dan komputer klien akan langsung menyala dengan image yang kita sediakan pada server.

Pada penulisan ini penulis hanya melakukan percobaan pada 5 komputer klien.

\section{SIMPULAN}

Dengan diimplementasikannya system diskless dengan menggunakan aplikasi CCBoot ini. Pemilik usaha dan laboratorium komputer dapat menghemat biaya dan waktu dalam perawatan hardware dan software, dan juga penghematan dalam pembelian lisensi OS (Operating System).

Pengehematan biaya dilakukan dalam pemangkasan pembelian Hardware yaitu tidak diperlukannya lagi harddisk pada setiap klien, dan pembelian Lisensi OS dan aplikasi/perangkat lunak (Software).

Dengan menggunakan sistem ini, para pelaku usaha warnet dan laboratorium komputer dapat dengan mudah melakukan perawatan pada software yang dimiliki, sehingga setiap terjadinya kerusakan tidak mengeluarkan biaya dan waktu dalam perbaikan secara banyak (umum).

\section{DAFTAR PUSTAKA}

Ardian, Ferry. 2011. Perancangan Jaringan Komputer Diskless Berbasis Windows - Linux Terminal Server Project (WLTSP) Pada Sistem Operasi Windows XP Professional dan Ubuntu 9.04. Bandung: Intitut Teknologi Telkom.

Syani, Mamay. 2017. Analisis Dan Implementasi Jaringanclient Server Berbasis Thin Client Menggunakan Jaringan Mini Komputer Di Laboratorium Jaringan Politeknik Tedc Bandung. Kusuma, D. A. (2015). Perancangan Jaringan Diskless Menggunakan 
Program

CCBOOT. http://doi.org/10.1017/CBO97811 07415324.004

Shinoda, M. (2014). Pengertian Dan Macam Macam Topologi Jaringan Komputer. Retrieved January 15, 2016, from http://www.adalahcara.com/2014/ 09/ macam-pengertiantopologijaringan-komputer.html

Jatmiko, F. W. (2011). Analisa Sistem Diskless Pada Windows 2000 Server Dan Nlinux Redhat 9.0, 6-

Rakhmat, Harry. 2014. Perancangan Jaringan Komputer Diskless Berbasis Linux Terminal Server Project Pada Sistem Operasi UBUNTU 8.04. Jurnal Elektro Telekumunikasi Terapan. http://journals.telkomuniversity.ac. $i$ d/jett/article/download/80/29/

Punthawanunt, Suphanchai. 2018. Fully Automated Diskless Deployment for University's Lab. Kasem Bundit Engineering Journal. Vol.8 No.2 2018.

https://www.tcithaijo.org/index.php/kbej/article/do wnload/118408/107026/
Salah. K. 2011. Toward Green Computing using Diskless High Performance Cluster.

https://www.simpleweb.org/ifip/Co nferences/CNSM/2011/papers/856 64_1.pdf

Kulthida, Phanpikhor. 2013. Performance comparison of the diskless technology. Proceedings of the 10th International Joint Conference on Computer Science and Software Engineering. (JCSSE 2013).

Ferrie, Gregg. The Benefits of Managed Diskless Client Technologies in an Educational Environment, Athbasca University, Alberta, 2011.

Montanaro, G.D. Workstation as environments for the analysis and design of control systems.

Daga, Abhijeet. 2015. Survey of Diskless Workstation. Global Journal of Engineering Science and Researches. 